\title{
High performance cellulose nanocomposites: Comparing the reinforcing ability of bacterial cellulose and nanofibrillated cellulose
}

Koon-Yang Lee ${ }^{1}$, Tekla Tammelin ${ }^{2 *}$, Kerstin Schulfter ${ }^{3}$, Harri Kiiskinen ${ }^{4}$, Juha Samela $^{4}$ and Alexander Bismarck ${ }^{1^{*}}$

${ }^{1}$ Polymer and Composite Engineering (PaCE) Group, Department of Chemical Engineering, Imperial College London, South Kensington Campus, London, SW7 2AZ, UK

${ }^{2}$ VTT Technical Research Centre of Finland, P.O. Box 1000, FIN-02044 VTT, Finland

${ }^{3}$ Forschungszentrum Medical Technology and Biotechnology (fzmb) GmbH, D-99947 Bad Langensalza, Germany

${ }^{4}$ VTT Technical Research Centre of Finland, P.O. Box 1603, FIN-40101, Jyväskylä, Finland

${ }^{*}$ Corresponding authors: email: a.bismarck@imperial.ac.uk, tel: +44 (0)2075945578, fax: +44 (0)2075945638; email: tekla.tammelin@vtt.fi, tel: +358207224632

\begin{abstract}
This work investigates the surface and bulk properties of nanofibrillated cellulose (NFC) and bacterial cellulose (BC), as well as their reinforcing ability in polymer nanocomposites. $\mathrm{BC}$ possesses higher critical surface tension of $57 \mathrm{mN} \mathrm{m}^{-1}$ compared to NFC $\left(41 \mathrm{mN} \mathrm{m}^{-1}\right)$. The thermal degradation temperature in both nitrogen and air atmosphere of $\mathrm{BC}$ was also found to be higher than that of NFC. These results are in good agreement with the higher crystallinity of $\mathrm{BC}$ as determined by $\mathrm{XRD}$, measured to be $71 \%$ for $\mathrm{BC}$ as compared to NFC of $41 \%$. Nanocellulose papers were prepared from BC and NFC. Both papers possessed similar tensile moduli and strengths of 12 GPa and $100 \mathrm{MPa}$, respectively. Nanocomposites were manufactured by infusing the nanocellulose paper with an epoxy resin using vacuum assisted resin infusion. The cellulose reinforced epoxy nanocomposites had a stiffness and strength of approximately $\sim 8 \mathrm{GPa}$ and $\sim 100 \mathrm{MPa}$ at an equivalent fibre volume fraction of 60 vol.-\%. In terms of the reinforcing ability of NFC and BC in a polymer matrix, no significant difference between NFC and BC was observed.
\end{abstract}

Keywords: Nanofibrillated cellulose, bacterial cellulose, resin infusion, nanocomposites, mechanical properties 


\section{Introduction}

Cellulose is used in the paper, ${ }^{1}$ pharmaceutical and cosmetic industries, ${ }^{2,3}$ explored as reinforcement for polymers ${ }^{4-7}$ and natural fibre reinforced polymer nanocomposites. ${ }^{8-}$ ${ }^{11}$ Numerous products are also derived from cellulose; technical textile fibres, such as viscose and Lyocell ${ }^{12}$ and thermoplastic polymers, such as cellulose acetate. Currently, much research activity and attention focused on the isolation and production of nano-scale cellulose fibres. For comprehensive reviews on the production and application of nanocellulose the readers are referred to publications by Klemm at al. ${ }^{13}$ and Siró et al. ${ }^{14}$ Interests in nanocellulose comes from the fact that nano-scale cellulose combines the physical and chemical properties of cellulose, such as hydrophilicity and the ability to be chemically modified by a broad range of reactions, with other features such as high specific surface area and aspect ratio.

Nanocellulose can be obtained by two approaches: top-down and bottom-up. The top-down approach involves the disintegration of (ligno)cellulose biomass, such as wood fibres into nanofibres. This technique was first reported by Herrick et al. ${ }^{15}$ and Turbak et al., ${ }^{16}$ whereby wood pulp was fed through a high-pressure homogeniser to reduce the size of the fibres down to the nano-scale. A more recent method of producing nanocellulose from plant-based cellulosic fibres involves using grinders, ${ }^{17}$ whereby wood pulp is passed through the slit between a static and rotating grindstone. This high shear fibrillation process converts micrometre-sized cellulose into nanocellulose. Herein, we term these plant derived nano-scale cellulose nanofibrillated cellulose (NFC). Nanocellulose produced via the bottom-up approach utilises the fermentation of low molecular weight sugar using cellulose-producing bacteria, such as from the Acetobacter species, to produce nanocellulose. ${ }^{2,18-20}$ These nanocellulose, herein termed bacterial cellulose $(\mathrm{BC})$, is pure cellulose without the presence of hemicellulose, pectin or lignin. ${ }^{21}$ The cellulose is excreted by the bacteria into the aqueous culture medium directly as nanofibres, with a diameter ranging from $25-100 \mathrm{~nm} .{ }^{19,21}$ These nanofibres makes up the pellicles in the culture medium. ${ }^{19}$

Utilising nanocellulose as filler in polymer matrices was first reported by Favier et al. ${ }^{22}$ The authors reinforced latex (styrene-butyl acrylate copolymer) with cellulose nanowhiskers derived from tunicin to produce polymer nanocomposites. Since then, studies on utilising nanocellulose as filler in polymer matrices have increased significantly over the years. The major driver for this is the potential of exploiting the high stiffness of cellulose crystals. X-ray diffraction, Raman 
spectroscopy and numerical simulations estimated the stiffness of a cellulose crystal to be approximately $100-160 \mathrm{GPa},{ }^{23-25}$ which is highly desirable as reinforcing filler for polymer matrices. However, it is not clear what is the true crystal modulus of cellulose nor its maximum attainable stiffness as reinforcing filler. ${ }^{26}$ Nonetheless, nanocellulose has been shown to improve the mechanical performance of the resulting nanocomposites. Yano et al. ${ }^{27}$ have obtained a tensile modulus and strength of up to $21 \mathrm{GPa}$ and $325 \mathrm{MPa}$, respectively, for a $\mathrm{BC}$ paper reinforced epoxy resin with a nanocellulose loading of $70 \mathrm{wt} .-\%$. However, the authors failed to explain why the tensile strength of the nanocomposites was $25 \%$ higher than that of the reinforcing BC papers. Nevertheless, this study showed that high strength nanocomposites can be produced using BC papers. Laminated BC-polylactide nanocomposites at a loading fraction of 18 vol.- $\%$ have also been studied. ${ }^{28}$ The tensile modulus doubled and the strength tripled when compared to neat polylactide. NFC, if incorporated into polymers, has also shown to significantly improve the mechanical properties of the polymer. Henriksson et al. ${ }^{29}$ produced NFC paper reinforced hexamethoxymethyl melamine-based nanocomposites; at a volume fraction of 55 vol.-\%, a Young's modulus of 9.7 GPa and tensile strength of $108 \mathrm{MPa}$ was achieved. The neat polymer possesses a Young's modulus and tensile strength of only $3.6 \mathrm{MPa}$ and $6.1 \mathrm{MPa}$, respectively.

It is evident that $\mathrm{BC}$ and $\mathrm{NFC}$ have the ability to act as reinforcement for the production of high strength and stiffness materials. Whilst the deformation mechanics of BC and NFC paper have been studied recently, ${ }^{30}$ there are currently no systematic studies reporting the surface and bulk properties of NFC and BC, and the reinforcing capability of these two types of nanocellulose for composite materials. With nanocellulose gaining significant research interest and wide availability ${ }^{\dagger}$, it is important to quantify the differences, if any, between NFC and BC. Therefore, the aim of this work is to elucidate the differences or similarities of NFC and BC in terms of their wettability, $\zeta$-potential, crystallinity, thermal degradation behaviour and mechanical properties. This article also demonstrates the large scale manufacturing of nanocomposites using commercially available vacuum assisted resin infusion, which is intrinsically scalable and discusses the reinforcing ability of NFC and BC in nanocomposites applications.

\footnotetext{
${ }^{\dagger}$ NFC can be obtained from wood pulp via grinder or high-pressure homogenizer. fzmb GmbH is currently producing $30 \mathrm{t}$ per annum of $\mathrm{BC}$.
} 


\section{Experimental section}

Materials. n-Hexane (GPR RECTAPUR, purity $\geq 95 \%$ ), dimethyl sulfoxide (analytical reagent, purity $\geq 99.5 \%$ ) and water (HiperSolv CHROMANORM, purity $\geq$ 99.5\%) were purchased from VWR. n-Dodecane (purity $\geq 99 \%$ ) and formamide (purity $\geq 99.5 \%$ ) were purchased from Acros Organics. Ethylene glycol (Aldrich, purity $\geq 99 \%$ ) was purchased from Sigma-Aldrich. All these chemicals were used without purification for wicking rate measurement of NFC and BC. Ultra low viscosity epoxy resin (PRIME 20ULV, Gurit Ltd, Isle of Wight \& Hamble, UK) was used as the matrix for the nanocomposites. BC was kindly supplied by fzmb $\mathrm{GmbH}$ (Bad Langensalza, Germany) in wet pellicle form containing 94 wt.- $\%$ water. NFC was produced by grinding of never-dried bleached birch kraft pulp (Betula pendula). The grinding of birch pulp was conducted using a Masuko Mass Colloider (Masuko Sangyo Co., Kawaguchi, Japan). The pulp was passed through the grinder seven times and the final consistency of the aqueous gel-like NFC was approximately $2 \mathrm{wt}-\%$.

Large scale manufacturing of BC and NFC papers. BC and NFC papers with a grammage of $60 \mathrm{~g} \mathrm{~m}^{-2}$ were produced using a home-made vacuum assisted paper former equipment designed by VTT in cooperation with Metso Paper (Finland). Firstly, the $\mathrm{BC}$ pellicles were cut into small pieces and blended for $2 \mathrm{~min}$ at a consistency of $0.1 \mathrm{wt} .-\%$. The NFC suspension was adjusted to $0.4 \mathrm{wt} .-\%$ from 2 wt.$\%$ consistency and blended for $2 \mathrm{~min}$ to produce a homogenous dispersion of nanocellulose in water. These nanocellulose suspensions were then vacuum filtered onto a filter. The filter cake was then wet pressed twice under a weight of $10 \mathrm{~kg}$ between blotting papers for $10 \mathrm{~s}$. The partially dried nanocellulose papers from the wet pressing steps were then sandwiched between blotting papers and metal plates under a weight of $10 \mathrm{~kg}$ during the drying process in the oven held at $55^{\circ} \mathrm{C}$ for at least $48 \mathrm{~h}$ to dry. This was to prevent the nanocellulose papers from shrinking. Shrinkage of cellulose papers will induce flexibility in the fibre network and decrease the load bearing capability of the resulting papers. ${ }^{31}$ 
Manufacturing of $\mathrm{BC}$ or NFC paper reinforced nanocomposites. The nanocellulose paper reinforced epoxy was produced using vacuum assisted resin infusion (VARI). A schematic diagram of the VARI lay-up is shown in Figure 1. A polyester porous flow medium (15087B, Newbury Engineer Textile, Berkshire, UK) was placed on top of the tooling side (a $460 \mathrm{~mm}$ x $920 \mathrm{~mm}$ heating plate with a temperature control unit), which consisted of a layer of polyester film (Melinex PW 122-50-RL, PSG group, London UK). Eleven nanocellulose papers were laid up and sandwiched between two PTFE coated glass release fabrics (FF03PM, Aerovac, West Yorkshire, UK) and placed on top of the polyester porous flow medium. Another polyester porous flow medium was then placed on top of the release fabric. The whole setup was covered with a vacuum bagging film (Capran 519 heat stabilised Nylon 6 blown tubular film, Aerovac, West Yorkshire, UK) and sealed using a vacuum sealant tape (SM5127, Aerovac, West Yorkshire, UK).

Prior to the infusion, the epoxy and hardener were mixed thoroughly at a ratio of 100:19 by weight and degassed at room temperature under a reduced pressure of 75 $\mathrm{mmHg}$ for $5 \mathrm{~min}$. This ensures all air bubbles trapped during the mixing process were removed. The infusion process starts with an air removal step, whereby a vacuum was applied to the system via the tubing on the non-tooling side with the resin inlet tubing sealed off. When the maximum vacuum was reached $(\sim 15 \mathrm{mmHg})$, the VARI setup was left under this vacuum for $2 \mathrm{~h}$ to ensure that there was no leakage in the set up by constantly monitoring the pressure in the vacuum bag. Once the system was determined to be leakage-free, the liquid resin was fed at room temperature from the bottom of the polyester porous flow medium on the tooling side through the nanocellulose papers and exit via the tubing on the non-tooling side. The inlet and outlet of the system were sealed off again when the resin fully impregnated the nanocellulose papers. The resin was left to cure at room temperature for $24 \mathrm{~h}$, followed by a post-curing step conducted at $50^{\circ} \mathrm{C}$ for $16 \mathrm{~h}$.

\section{Characterisation of nanocellulose and its nanocomposites}

Scanning electron microscopy (SEM). SEM was used to study the morphology of NFC and BC nanofibres. It was performed using a high-resolution field emission gun scanning electron microscope (LEO Gemini 1525 FEG-SEM, Oberkochen, Germany). The accelerating voltage used was $5 \mathrm{kV}$. Prior to SEM, the nanocellulose in water suspension was dropped onto carbon tabs stuck on the SEM stubs, air dried 
and $\mathrm{Cr}$ coated (K550 sputter coater, Emitech Ltd, Ashford, Kent, UK) for $1 \mathrm{~min}$ at 75 $\mathrm{mA}$.

Filtration time of nanocellulose suspension. The filtration time of nanocellulose suspension was characterised in order to quantify any difference between the behaviour of the nanocellulose suspension during filtration for the manufacturing of nanocellulose papers. This measurement was conducted by monitoring the decrease in the height of the nanocellulose suspension under vacuum assisted filtration $(\sim 150$ $\mathrm{mmHg}^{\dagger}$ ) in an $11 \mathrm{~mm}$ diameter Büchner funnel as a function of time. The hydrodynamic diameter of the nanocellulose in suspension can be approximated using Stoke's law for small Reynolds numbers:

$d_{H}^{2}=\frac{18 \times \eta \times u}{\left(\rho_{c}-\rho_{w}\right) g}$

where $\eta, u, \rho_{c}, \rho_{w}, g$ denote the viscosity of water, settling velocity of agglomerated cellulose, density of cellulose, density of water and gravitational acceleration, respectively. The settling velocity can be approximated by taking the first derivative of the height-time curve.

X-ray diffraction (XRD) to determine the crystallinity of nanocellulose. The XRD pattern of NFC and BC nanofibres was measured using an X-ray diffractometer (PANalytical X'pert Pro, PANalytical Ltd, Cambridge, UK) equipped with $1.54 \AA \mathrm{Cu}$ $\mathrm{K} \alpha \mathrm{X}$-ray source. Measurements were taken from $2 \theta=10^{\circ}$ to $40^{\circ}$ using a step size and scan speed of $0.05^{\circ}$ and $0.2^{\circ} \mathrm{s}^{-1}$, respectively. The crystallinity of the nanocellulose was calculated based on the area under the curve of the XRD diffraction pattern using:

$\chi_{c}=\frac{A_{c}}{A_{c}+A_{a}} \times 100 \%$

where $A_{c}$ and $A_{a}$ are the total crystalline and amorphous areas, respectively, between the measured Bragg's angles. Scherrer's equation, ${ }^{32}$

$L_{002}=\frac{0.91 \times \lambda}{\beta \times \cos \theta}$

\footnotetext{
${ }^{\dagger}$ This is the reduced pressure used in the manufacturing of nanocellulose paper.
} 
where $\theta, \beta$, and $\lambda$ are the Bragg's angle (in degrees), full width at half maximum of the 002 reflection and wavelength of the X-ray source used, respectively, was used to determine the crystallite size and hence, the structural order of the 002 reflection $\left(L_{002}\right)$.

Oxygen transmission rate (OTR) of NFC and BC papers. Oxygen transmission rate measurements were performed with Oxygen Permeation Analyser Model 8001 (Systech Instruments Ltd. UK). The tests were carried out at $23{ }^{\circ} \mathrm{C}$ and $82 \%$ relative humidity.

Determining the critical surface tension $\left(\gamma_{c}\right)$ of NFC and BC nanofibres. $\gamma_{c}$ of NFC and BC nanofibres were determined from wicking measurements. ${ }^{33}$ The nanocellulose papers were cut into rectangular strips of $5 \mathrm{~mm} \times 20 \mathrm{~mm}$. One end of the strip was mounted onto an ultra sensitive microbalance (Type 4505 MP8-1, Sartorius ultramicro, Göttingen, $\mathrm{GmbH}$ ). The reservoir containing the test liquid is moved upwards towards the other end of the strip until it touches the sample, then the movement of the reservoir was immediately stopped. This ensures that the mass gain of the papers is only a result of the penetration of the test liquid into the nanocellulose strips due to capillarity. During the measurement, the mass gain of the strip was recorded as a function of time. A total of 5 strips were tested for each test liquid. These data were then evaluated using the Washburn equation for a single capillary, ${ }^{34}$ which is derived from the combination of the Laplace and Hagen-Poiseuille equations for steady state, laminar flow through a capillary neglecting gravity:

$\gamma_{l v} \cos \theta=\left[\frac{2}{A^{2} r}\right]\left[\frac{\eta}{\rho^{2}}\right]\left[\frac{m^{2}}{t}\right]$

where $\gamma_{l v}, \eta, \rho$, are the surface tension, viscosity and density of the test liquid, respectively, and $m, A, r, \theta$ and $t$ are the mass gain due to capillarity, cross-sectional area of the capillary, radius of the capillary, contact angles and time, respectively.

However, for the case of these nanocellulose papers, the geometry of the capillary is unknown. Therefore, the factor $\left[\frac{2}{A^{2} r}\right]$ can be grouped into a factor $\left[\frac{1}{C}\right]$ and assuming the geometry of the capillary is constant ${ }^{35}$ throughout the measurement, we arrive at the following equation: 


$$
C \gamma_{l v} \cos \theta=\left[\frac{\eta}{\rho^{2}}\right]\left[\frac{m^{2}}{t}\right]
$$

By performing this measurement using a series of different test liquids with known $\gamma_{l v}$, the critical surface tension of the solid, $\gamma_{c}$, which corresponds to the maximum of the $\left[\frac{m^{2}}{t}\right]\left[\frac{\eta}{\rho^{2}}\right]=f\left(\gamma_{l v}\right)$, can be determined. ${ }^{33}$ The properties of the test liquids are summarised in Table 1.

Electrokinetic behaviour of NFC and BC. The electrokinetic behaviour of the nanocellulose was evaluated using $\zeta$-potential measurements (EKA, Anton Paar, Graz, Austria) based on streaming potential method. In order to exclude any overlaying effects due to the swelling of the nanocellulose or extraction of watersoluble components from the samples, the $\mathrm{pH}$ dependency of $\zeta$-potential was measured only after a time dependent $\zeta$-potential measurement in $1 \mathrm{mM} \mathrm{KCl}$ electrolyte was completed. During the $\zeta=\mathrm{f}(t)$ measurement, the streaming potential was generated by applying a steady pressure increase to 250 mbar across a channel, which was created by stacking two nanocellulose papers between a PTFE channel. The $\mathrm{pH}$ dependency of the $\zeta$-potential was then measured by changing the $\mathrm{pH}$ of the 1 $\mathrm{mM} \mathrm{KCl}$ electrolyte solution by adding $0.1 \mathrm{~N} \mathrm{HCl}$ or $\mathrm{KOH}$ using a titration unit (RTU, Anton Paar, Graz, Austria).

\section{Thermal stability of NFC and BC nanofibres: thermogravimetry analysis (TGA).} The thermal degradation behaviour of NFC and BC nanofibres was investigated using TGA (TGA Q500, TA Instruments, UK). Samples of $5 \mathrm{mg}$ were heated from room temperature to $600^{\circ} \mathrm{C}$ at a heating rate of $10^{\circ} \mathrm{C} \mathrm{min}^{-1}$ in nitrogen and air $\left(60 \mathrm{~mL} \mathrm{~min}^{-1}\right)$ atmosphere.

Density of nanocellulose papers and their nanocomposites. He pycnometry (AccuPyc 1330, Micromeritrics Ltd, Dunstable, UK) was used to measure the true density of nanocellulose papers and their nanocomposites. The volume fractions of nanocellulose in the composites are then back calculated from their respective densities. The thickness of the nanocellulose papers was measured using a micrometre calliper. With the thickness known, the bulk volume was calculated and the bulk 
density was determined by taking the ratio between the mass and the bulk volume of the evaluated paper. The porosity $(P)$ was then calculated using:

$P(\%)=\left(1-\frac{\rho_{\text {bulk }}}{\rho_{\text {papers }}}\right) \times 100$

where $\rho_{\text {bulk }}$ and $\rho_{\text {papers }}$ are the bulk and true density of the nanocellulose papers, respectively.

Tensile properties of the nanocellulose papers and nanocomposites. Nanocellulose papers were cut into dog bone shape specimens using a Zwick cutter. The test specimen possesses an overall length of $35 \mathrm{~mm}$ and the narrowest part of the specimen is $2 \mathrm{~mm}$. Prior to the test, the specimens were secured onto testing cards using a two-part cold curing epoxy resin (Araldite 2011, Huntsman Advanced Materials, Cambridge, UK). This was to prevent the clamp of the tensile testing equipment from damaging the test specimens. Tensile test was conducted using a TST350 tensile tester (Linkam Scientific Instruments, Surrey, UK). The load cell and crosshead speed used were $200 \mathrm{~N}$ and $1 \mathrm{~mm} \mathrm{~min}^{-1}$, respectively. The sample thickness was determined using a digital micrometre. A total of 5 specimens were tested for each type of nanocellulose. The machine compliance was determined to be $7.19 \times 10^{-3}$ $\mathrm{mm} \mathrm{N}^{-1}$.

The nanocomposites were tested in tension using an Instron universal material testing equipment (Instron 4505, Instron Corporation, MA, USA). The tensile test was conducted in accordance to ASTM D3039-00 using a load cell of $10 \mathrm{kN}$. The test specimens possessed dimensions of $100 \times 10 \times 1 \mathrm{~mm}$, with a gauge length of $40 \mathrm{~mm}$. Prior to the test, woven glass fibre reinforced polyester end tabs with $1.6 \mathrm{~mm}$ thickness were glued onto the samples using a two-part cold curing epoxy resin (Araldite 2011, Huntsman Advanced Materials, Cambridge, UK). The distance between the end tabs were $60 \mathrm{~mm}$. Strain gauges (FLA-2-11, Techni Measure, Studley, UK) were glued onto the middle portion of the test specimen using cyanoacrylate glue (EVERBUILD Building Products Ltd, Leeds, UK). Specimens were tested until failure at a crosshead speed of $1 \mathrm{~mm} \mathrm{~min}^{-1}$. A total of 5 specimens were tested for each type of nanocomposites.

\section{Results and discussions}




\section{Morphology of NFC and BC}

The morphology of the two different forms of nanocellulose was studied using scanning electron microscopy (SEM) (see Figure 2). Both types of nanocellulose possess a fibrous structure with dimensions of approximately $50 \mathrm{~nm}$ in diameter and several micrometres in length. It can also be seen that the diameter of the nanofibres are very uniform. This is not surprising for $\mathrm{BC}$ as its production is well-controlled by the biosynthesis of cellulose producing bacteria, whereby the nanocellulose is excreted by bacteria and assembled into the ribbon-shaped nanofibres. ${ }^{36}$ The production of NFC, on the other hand, was carried out by grinding birch kraft pulp using Masuko Mass Colloider. The pulp was passed through the grinder several times to ensure a uniform fibre diameter. ${ }^{37}$ NFC contains approximately $25 \%$ of amorphous xylan, which enhances the fibrillation procedure. In addition to this, both the NFC and BC papers are translucent (see Figure 3). The NFC paper is more transparent compared to BC papers. This could be due to the better disintegration and distribution of individual nanofibres within the paper structure. It is also evident from Figure 4 that the filtration time for BC suspension is faster than that of NFC suspension, which implies that the effective particle size of BC in suspension is larger than that of NFC. The hydrodynamic diameters of the nanocellulose in suspension were estimated to be $34 \mu \mathrm{m}$ and $16 \mu \mathrm{m}$ for $\mathrm{BC}$ and NFC, respectively. In addition to this, the slower filtration time of NFC suspension could be attributed to the swelling of NFC. NFC swells more than $\mathrm{BC}$ (see zeta potential section). As a result, the filter cake formed by NFC is less permeable than BC. BC and NFC papers made from suspensions (grammage of $60 \mathrm{~m}^{2} \mathrm{~g}^{-1}$ ) were $79 \mu \mathrm{m}$ and $64 \mu \mathrm{m}$ thick, respectively. In addition to this, the slight difference in thickness may affect the transparency of the papers. ${ }^{38}$

\section{Crystallinity of NFC and BC}

The XRD patterns of NFC and BC are shown in Figure 5. The diffraction pattern of $\mathrm{BC}$ exhibited the typical diffraction peaks of native cellulose at $14^{\circ}, 16^{\circ}, 22.5^{\circ}, 34^{\circ}$, which corresponds to the diffraction plane of $101,10 \overline{1}, 002$ and 040 , respectively. ${ }^{39}$ The diffraction pattern of NFC showed two broad peaks centred around $15^{\circ}$ and $22.5^{\circ}$. Similar diffraction patterns were also observed by Leppänen et al. ${ }^{40}$ native (cotton) cellulose exhibited two distinct peaks corresponding to $101,10 \overline{1}$ but kraft pulp exhibited only one broad peak around $15^{\circ}$. The absence of two distinct peaks 
around $2 \theta=14^{\circ}-16^{\circ}$ can be attributed to the presence of non-cellulosic compounds such as hemicellulose in NFC and the difference in cellulose crystal structures of NFC.

The crystallinity of all the samples was calculated based on the area under the curves of the diffraction pattern (see equation 2), instead of the more commonly used Segal equation. ${ }^{41}$ These results are tabulated in Table 2. Segal's equation is a semiempirical equation derived for native cellulose (cotton) without any impurities and therefore, the crystallinity obtained for NFC using this equation would not be accurate. BC possesses a higher crystallinity compared to NFC (see Table 2). BC also possesses a larger crystallite size and smaller d-spacing compared to NFC. This is due to the fact that NFC possesses high content of amorphous hemicelluloses, mainly xylan whereas cellulose content of the BC is higher than $99 \%$. The cellulose of NFC could also be less crystalline than cellulose produced by bacteria. The carbohydrate composition of the pulp and the NFC produced from it are very similar. The composition is $73 \%$ glucose, $26 \%$ xylose and $1 \%$ mannose. ${ }^{42}$ The pulp contains also $0.2 \%$ residual lignin and $0.09 \%$ residual extractives. ${ }^{43}$ In addition to this, the difference in the crystallite size and d-spacings of NFC and BC could be ascribed to the difference in crystal structures between the two types of cellulose. BC is predominantly cellulose-I $\alpha$ whereas plant-based cellulose such as NFC is predominantly cellulose-I $\beta .{ }^{39}$ This difference in the types of crystal structures result in the observed difference in crystallite size and d-spacings. ${ }^{44}$

\section{Wetting behaviour and critical surface tension of BC and NFC}

Wicking of test liquids into nanocellulose paper was used to characterise the wetting kinetics of nanocellulose and to determine the surface energy. Typical wetting curves are shown in Figure 6. The initial slope is a result of capillary effect imbibing the wetting liquids while the plateau is caused by the balance between capillarity and gravity. ${ }^{33}$ By evaluating the initial slope of wetting curves, a plot of the normalised wetting rate (right hand side of equation 5) against the surface tension of the test liquids can be produced (see Figure 7). This plot exhibits a maximum point, which is analogous to the Zisman's critical solid-vapour surface tension of the investigated nanocellulose. ${ }^{33}$ The liquids with surface tensions to the left of the maximum will fully wet the nanocellulose whilst partial wetting is observed for liquids having 
surface tensions to the right of the maximum. The data points shown in Figure 7 were fitted with a polynomial curve. The maximum point, corresponding to the critical surface tension of cellulose, which is defined as the surface tension of an imaginary liquid just wetting a solid completely, is summarised in Table 3. BC has a $\gamma_{c}$ of 57.0 $\mathrm{mN} \mathrm{m} \mathrm{m}^{-1}$ compared to NFC of $41.7 \mathrm{mN} \mathrm{m}^{-1}$. The high $\gamma_{c}$ value for BC agrees well with those measured by IGC $^{45}$ and could be ascribed to its high crystallinity ${ }^{45,46}$ and purity. ${ }^{47}$ On the other hand, NFC is a composite material consisting of cellulose and hemicellulose and both constituents will contribute to the overall solid surface tension of NFC. The surface tension of hemicellulose was found to be lower than that of cellulose. ${ }^{47}$ This results in the observed lower surface tension of NFC compared to BC.

\section{Streaming potential of NFC and BC papers}

$\zeta$-potential provides information regarding the surface chemistry of a material, the formation and composition of the electrochemical double layer when this material is in contact with an aqueous electrolyte solution. Figure 8 shows the streaming $\zeta$ potential of NFC and $\mathrm{BC}$ as a function of $\mathrm{pH}$. The formation of the electrochemical double layer is predominantly due to the dissociation of Brønsted acid/base groups and adsorption of electrolyte ions onto the surface. The $\zeta$-potential shows a plateau at high $\mathrm{pH}$, indicating that the surface is acidic as all dissociable functional groups, such as $-\mathrm{OH}$ group, are fully deprotonated. As the $\mathrm{pH}$ decreased, the $\zeta$-potential increases due to protonation of functional groups. As the $\mathrm{pH}$ is decreased further, the $\zeta$ potential reaches zero, which corresponds to the isoelectric point (iep) of the investigated surface. This is the point where no net charge is present on the surface. After iep, a further decrease in $\mathrm{pH}$ resulted in the drastic increase in $\zeta$-potential due to the adsorption of protons $\left(\mathrm{H}_{3} \mathrm{O}^{+}\right)$onto the surface.

Table 3 summarises the iep and the plateau values of $\zeta$-potential $\left(\zeta_{\text {plateau }}\right)$ of NFC and BC. NFC and BC possess iep of $\mathrm{pH}=3.8$ and 3.2, respectively. The iep is governed by the $\mathrm{pK}_{\mathrm{a}}$ of all the dissociable functional groups present. ${ }^{48}$ In the case of $\mathrm{BC}$, the iep is due to dissociation of $-\mathrm{OH}$ groups in cellulose molecules, with $\mathrm{pK}_{\mathrm{a}}$ values of between 2.5 and 3.4 (estimated based on purified cotton cellulose). ${ }^{49}$ On the other hand, the dissociable functional groups in NFC include the $-\mathrm{OH}$ and/or carboxyl $(-\mathrm{COOH})$ groups present in the cellulose and hemicellulose, such as xylan and 
glucose, which possess $\mathrm{pK}_{\mathrm{a}}$ values of $3.7^{50}$ and $5.6,{ }^{51}$ respectively. The observed more negative value of $\zeta_{\text {plateau }}$ for BC compared to NFC can also be attributed to the low crystallinity and high hemicellulose content of NFC. Hemicellulose is known to swell in water. ${ }^{52}$ The lower crystallinity of NFC also enhances the swelling effect due to the high water uptake. ${ }^{53}$ This swelling of NFC causes the transfer of the plane of shear into the electrolyte which excludes the diffusive part of the electric double layer from mechanical and electrical interaction. ${ }^{54}$ This is also supported by the $\Delta \zeta$ obtained from $\zeta=\mathrm{f}(t)$ measurement. The quotient $\Delta \zeta=\left(\zeta_{\infty}-\zeta_{0}\right) / \zeta_{0}$ provides an indication of the degree of swelling of the investigated surface. ${ }^{55}$ The larger $\Delta \zeta$ value of NFC (low crystallinity) indicates a higher degree of swelling compared to $\mathrm{BC}$ (high crystallinity), which possesses a lower $\Delta \zeta$ value. These results are in good agreement with the observed more negative $\zeta_{\text {plateau }}$ value for BC compared to NFC.

\section{Thermal degradation behaviour of NFC and BC}

The thermal degradation behaviour of NFC and BC is shown in Figure 9. The onset degradation temperatures in nitrogen and air are tabulated in Table 3. In nitrogen atmosphere, both the nanocellulose underwent a single step thermal degradation (see Figure 9, top). The initial weight loss in temperature range of $50-150^{\circ} \mathrm{C}$ is mainly due to removal of moisture from the cellulose. The thermal degradation occurring between temperatures of $250-400^{\circ} \mathrm{C}$ is attributed to the depolymerisation of hemicellulose (for NFC) and cleavage of glycosidic linkages of cellulose (for both NFC and BC). ${ }^{56}$ In air, a two-step thermal degradation behaviour for NFC and BC was observed (Figure 9, bottom). The initial weight loss between $300-350^{\circ} \mathrm{C}$ is attributed to the degradation of compounds with lower molecular weight first and the second decomposition step $\left(350-500^{\circ} \mathrm{C}\right)$ is attributed to the degradation of the sixmember cyclic structure of cellulose (pyran). ${ }^{57,}{ }^{58}$ Even though the thermal degradation behaviour of NFC and BC are very similar in nitrogen and air atmosphere, the onset degradation temperature of NFC is lower than that of BC. The earlier onset degradation of NFC can be attributed to its lower crystallinity compared to $\mathrm{BC}^{59}$

\section{Tensile properties of cellulose papers and nanocomposites}


Both types of nanocellulose papers possess similar stiffness and strength; $12.8 \pm 1.4$ $\mathrm{GPa}$ and $103 \pm 13 \mathrm{MPa}$, respectively for NFC paper, $12.0 \pm 1.1 \mathrm{GPa}$ and $123.7 \mathrm{MPa}$, respectively for BC paper (see Table 4 and the characteristic stress-strain curves are shown in Figure 10). These values are consistent with the mechanical properties of nanocellulose papers studied by Henriksson et al. ${ }^{29}$ and Iwamoto et al. ${ }^{60}$ At first glance, it seems surprising that BC papers, which have a much higher degree of crystallinity, possess almost the same elastic modulus as NFC. However, BC paper is more porous compared to NFC paper (see Table 5). The porosity of BC paper was found to be $52 \%$ compared to NFC paper of only $38 \%$. The oxygen transmission rates through the paper structures confirm this. The papers prepared using NFC possess lower oxygen transmission rates indicating more densely packed fibrillar network structure compared to the $\mathrm{BC}$ papers. We postulate that the larger fragments of the $\mathrm{BC}$ network (hydrodynamic diameter of $34 \mu \mathrm{m}$ ) as compared to the smaller NFC fibrils (hydrodynamic diameter of $16 \mu \mathrm{m}$ ) will affect the packing efficiency in the wet state, resulting in this higher porosity and thicker papers. Nevertheless, it is quite remarkable that $\mathrm{BC}$ papers with such a high porosity possess good mechanical properties. In addition to the difference in porosity of the papers, the presence of hemicellulose also affects the mechanical properties of NFC papers. Hemicellulose acts as adhesive for the nanofibres forming a composite, analogous to plant fibres. ${ }^{60,61}$ As a result, NFC with lower crystallinity and porosity possesses a similar strength and stiffness to BC (higher crystallinity and porosity). BC, on the other hand, has a higher strain-to-failure at $7.5 \%$ compared to NFC of only $4.2 \%$. The higher strain-to-failure of $\mathrm{BC}$ papers was probably be due to fewer physical crosslink points between the nanofibres, which allows for the realignment of the fibres during tensile loading. In addition to this, the presence of hemicellulose could also lead to the reduction in the strain-to-failure of NFC papers. Although hemicelluloses can improve the bonding within the nanofibres, which is postulated to be the result of film forming ability and natural affinity towards cellulose, the distinctive feature of the hemicellulose films is their brittleness. ${ }^{62}$ The tensile work of fracture $\left(\mathrm{W}_{\mathrm{A}}\right.$, calculated from the area under the stress-strain curve) was, as expected, smaller for NFC papers compared to BC papers.

A stack of 11 papers of NFC and BC paper were resin infused with an ultra low viscosity epoxy resin. This resin was chosen to ensure that the liquid will impregnate the nanocellulose papers. The surface tension of the liquid epoxy resin 
(with hardener) was measured ${ }^{\S}$ to be $32.3 \pm 0.1 \mathrm{mN} \mathrm{m}^{-1}$. This liquid resin should, therefore, fully wet both BC and NFC papers as the critical surface tension of the cellulose was higher than the surface tension of the resin. The manufactured nanocomposites possess different fibre volume fractions $\left(v_{f}\right)$. In order to be able to compare between the nanocomposites, the Young's moduli of the nanocomposites were normalised to an equivalent fibre volume fraction of 60 vol.-\% (see Table 6). Both NFC and BC exhibited excellent reinforcing ability when used in paper form as reinforcement due to the presence of the cellulose network structure in the reinforcement. The Young's modulus of the nanocomposites was $8 \mathrm{GPa}$ compared to that of the neat resin of only $3 \mathrm{GPa}$. This increase is inline with the modulus calculated using the "rules-of-mixtures" for composites ${ }^{\dagger}$ indicating that the maximum possible Young's modulus of the material was achieved. There is a slight difference in the reinforcing ability between NFC and BC when the tensile strength $(\sigma)$ was compared. BC reinforced nanocomposites possesses higher $\sigma$ compared to NFC reinforced nanocomposites, even when the former had a slightly lower $v_{f}$. We attribute this to the higher surface energy of $\mathrm{BC}$, which promotes better adhesion between the matrix and the reinforcing fibre. The higher elongation at break of $\mathrm{BC}$ paper reinforced nanocomposites compared to NFC nanocomposites is due to the higher strain-to-failure of the BC paper.

\section{Conclusions}

Nanocellulose obtained top-down (NFC) or bottom-up (BC) was studied and compared in this work. SEM showed that both types of nanocellulose posseses a fibrous structure of approximately $50 \mathrm{~nm}$ in diameter and several micrometre in length. BC had significantly higher degree of crystallinity (as measured by XRD) of $72 \%$ compared to NFC of $41 \%$. The lower crystallinity of NFC is attributed to the presence of non-cellulosic compounds, such as hemicellulose. NFC was derived from plant-based cellulose and possesses cellulose- $\mathrm{I}_{\beta}$ structure whereas $\mathrm{BC}$ possesses a cellulose I $\alpha$ structure. This difference in cellulose structures also resulted in difference in the cellulose crystallite size and d-spacings. The critical surface tension of NFC and $\mathrm{BC}$ was determined from the normalised wetting rates as determined by wicking

\footnotetext{
${ }^{\S}$ Surface tension was measured using pendant drop method performed on Easydrop (DSA 15B, Krüss, Hamburg, $\mathrm{GmbH})$ at $20^{\circ} \mathrm{C}$.

${ }^{\dagger}$ The moduli used in this calculation is $3 \mathrm{GPa}$ (for the matrix) and the modulus of the reinforcing nanocellulose papers (12.8 GPa for NFC and 12.0 GPa for BC).
} 
rate measurements. It was found that $\mathrm{BC}$ possesses a $\gamma_{\mathrm{c}}$ of $57 \mathrm{mN} \mathrm{m}^{-1}$. NFC, on the other hand, possesses lower $\gamma_{\mathrm{c}}$ of $41 \mathrm{mN} \mathrm{m}^{-1}$. $\zeta$-potentials indicate that both surfaces possess acidic characteristics. However, the more amorphous nature of NFC also resulting in a higher degree of swelling and, therefore, less negative $\zeta_{\text {plateau }}$ compared to $\mathrm{BC}$. In addition to this, the more crystalline nature of $\mathrm{BC}$ also resulted in higher thermal degradation temperature as studied by TGA compared to NFC.

Both the NFC and BC papers were found to possess similar tensile properties; a Young's modulus of $\sim 12 \mathrm{GPa}$ and tensile strength of $\sim 110 \mathrm{MPa}$. When used as reinforcement for an epoxy matrix, the nanocomposites were found to possess a high stiffness and strength of approximately $\sim 8 \mathrm{GPa}$ and $\sim 100 \mathrm{MPa}$, respectively at an equivalent fibre volume fraction of 60 vol.-\%. However, no significant difference was observed between the reinforcing ability of NFC and BC in terms of the stiffness of the nanocomposites. The nanocomposites reinforced with BC papers, however, showed slightly higher tensile strength compared to NFC papers by approximately $6 \%$. The higher elongation at break of $\mathrm{BC}$ paper reinforced nanocomposites compared to NFC paper reinforced nanocomposites is due to the higher strain-to-failure of the BC paper. Nonetheless, the difference between the tensile strength of the nanocomposites reinforced by NFC and BC is not very significant. This implies that both NFC and BC will serve as excellent reinforcing material for the production of nanocomposites.

Acknowledgements. The authors would like to thank the UK Engineering and Physical Science Research Council (EPSRC) (EP/F032005/1), VTT Technical Research Centre of Finland and the Deputy Rector Award of Imperial College London for funding KYL. The authors would also like to thank UPM-Kymmene for supplying the nanofibrillated cellulose used in this study.

\section{References}

1. Sczostak, A., Macromolecular Symposia 2009, 280, 45-53.

2. Klemm, D.; Heublein, B.; Fink, H. P.; Bohn, A., Angew. Chem.-Int. Edit. 2005, 44 (22), 3358-3393.

3. Kamel, S.; Ali, N.; Jahangir, K.; Shah, S. M.; El-Gendy, A. A., Express Polym. Lett. 2008, 2 (11), 758-778.

4. Pandey, J. K.; Ahn, S. H.; Lee, C. S.; Mohanty, A. K.; Misra, M., Macromol. Mater. Eng. 2010, 295 (11), 975-989. 
5. Satyanarayana, K. G.; Arizaga, G. G. C.; Wypych, F., Prog. Polym. Sci. 2009, 34 (9), 982-1021.

6. Blaker, J. J.; Lee, K. Y.; Bismarck, A., Journal of Biobased Materials and Bioenergy 2011, 5 (1), 1-16.

7. Lee, K. Y.; Blaker, J. J.; Bismarck, A., Compos. Sci. Technol. 2009, 69 (1516), 2724-2733.

8. Juntaro, J.; Pommet, M.; Kalinka, G.; Mantalaris, A.; Shaffer, M. S. P.; Bismarck, A., Adv. Mater. 2008, 20 (16), 3122-3126.

9. Pommet, M.; Juntaro, J.; Heng, J. Y. Y.; Mantalaris, A.; Lee, A. F.; Wilson, K.; Kalinka, G.; Shaffer, M. S. P.; Bismarck, A., Biomacromolecules 2008, 9 (6), 1643-1651.

10. Lee, K. Y.; Bharadia, P.; Blaker, J. J.; Bismarck, A., Compos. Pt. A-Appl. Sci. Manuf. 2012, DOI: 10.1016/j.compositesa.2012.06.013.

11. Lee, K. Y.; Ho, K. K. C.; Schlufter, K.; Bismarck, A., Compos. Sci. Technol. 2012, DOI: $10.1016 / j$.compscitech.2012.06.014.

12. Harms, H., Materialwiss. Werkstofftech. 2003, 34 (3), 267-271.

13. Klemm, D.; Kramer, F.; Moritz, S.; Lindstrom, T.; Ankerfors, M.; Gray, D.; Dorris, A., Angew. Chem.-Int. Edit. 2011, 50 (24), 5438-5466.

14. Siro, I.; Plackett, D., Cellulose 2010, 17 (3), 459-494.

15. Herrick, F. W.; Casebier, R. L.; Hamilton, J. K.; Sandberg, K. R. In Microfibrillated cellulose: morphology and accessibility, Proceedings of 9th Cellulose Conference, New York, Sarko, A., Ed. Wiley: New York, 1983; pp 797813.

16. Turbak, A. F.; Snyder, F. W.; Sandberg, K. R., Journal of Applied Polymer Science: Applied Polymer Symposium 1983, 37, 459-494.

17. Iwamoto, S.; Nakagaito, A. N.; Yano, H.; Nogi, M., Appl. Phys. A-Mater. Sci. Process. 2005, 81 (6), CP8-1112.

18. Brown, A. J., Journal of the Chemical Society, Transations 1886, 49, 172-187.

19. Jonas, R.; Farah, L. F., Polym. Degrad. Stabil. 1998, 59 (1-3), 101-106.

20. Ross, P.; Mayer, R.; Benziman, M., Microbiol. Rev. 1991, 55 (1), 35-58.

21. Iguchi, M.; Yamanaka, S.; Budhiono, A., J. Mater. Sci. 2000, 35 (2), 261-270.

22. Favier, V.; Canova, G. R.; Cavaille, J. Y.; Chanzy, H.; Dufresne, A.; Gauthier, C., Polym. Adv. Technol. 1995, 6 (5), 351-355.

23. Eichhorn, S. J.; Davies, G. R., Cellulose 2006, 13 (3), 291-307.

24. Matsuo, M.; Sawatari, C.; Iwai, Y.; Ozaki, F., Macromolecules 1990, 23 (13), 3266-3275.

25. Hsieh, Y. C.; Yano, H.; Nogi, M.; Eichhorn, S. J., Cellulose 2008, 15 (4), $507-$ 513.

26. Eichhorn, S. J.; Dufresne, A.; Aranguren, M.; Marcovich, N. E.; Capadona, J. R.; Rowan, S. J.; Weder, C.; Thielemans, W.; Roman, M.; Renneckar, S.; Gindl, W.; Veigel, S.; Keckes, J.; Yano, H.; Abe, K.; Nogi, M.; Nakagaito, A. N.; Mangalam, A.; Simonsen, J.; Benight, A. S.; Bismarck, A.; Berglund, L. A.; Peijs, T., J. Mater. Sci. 2010, 45 (1), 1-33.

27. Yano, H.; Sugiyama, J.; Nakagaito, A. N.; Nogi, M.; Matsuura, T.; Hikita, M.; Handa, K., Adv. Mater. 2005, 17 (2), 153-+.

28. Quero, F.; Nogi, M.; Yano, H.; Abdulsalami, K.; Holmes, S. M.; Sakakini, B. H.; Eichhorn, S. J., ACS Appl. Mater. Interfaces 2010, 2 (1), 321-330.

29. Henriksson, M.; Fogelstrom, L.; Berglund, L. A.; Johansson, M.; Hult, A., Compos. Sci. Technol. 2011, 71 (1), 13-17. 
30. Tanpichai, S.; Quero, F.; Nogi, M.; Yano, H.; Young, R. J.; Lindstrom, T.; Sampson, W. W.; Eichhorn, S. J., Biomacromolecules 2012, 13 (5), 1340-1349.

31. Vainio, A. K.; Paulapuro, H., Bioresources 2007, 2 (3), 442-458.

32. Patterson, A. L., Physical Review 1939, 56 (10), 978-982.

33. Troger, J.; Lunkwitz, K.; Grundke, K.; Burger, W., Colloids and Surfaces aPhysicochemical and Engineering Aspects 1998, 134 (3), 299-304.

34. Szekely, J.; Neumann, A. W.; Chuang, Y. K., J. Colloid Interface Sci. 1971, 35 (2), 273-\&.

35. Grundke, K.; Bogumil, T.; Gietzelt, T.; Jacobasch, H. J.; Kwok, D. Y.; Neumann, A. W., Wetting measurements on smooth, rough and porous solid surfaces. In Interfaces, Surfactants and Colloids in Engineering, Jacobasch, H. J., Ed. 1996; Vol. 101, pp 58-68.

36. Malcolm Brown Jr, R., Bacterial cellulose. In Cellulose: Structural and functional aspects, Phillips, G. O.; Kennedy, J. F.; Williams, P. A., Eds. Ellis Horwood Limited: 1989; pp 145-151.

37. Iwamoto, S.; Nakagaito, A. N.; Yano, H., Appl. Phys. A-Mater. Sci. Process. 2007, 89 (2), 461-466.

38. Nogi, M.; Iwamoto, S.; Nakagaito, A. N.; Yano, H., Adv. Mater. 2009, 21 (16), 1595-+.

39. Wada, M.; Okano, T.; Sugiyama, J., Journal of Wood Science 2001, 47 (2), 124-128.

40. Leppanen, K.; Andersson, S.; Torkkeli, M.; Knaapila, M.; Kotelnikova, N.; Serimaa, R., Cellulose 2009, 16 (6), 999-1015.

41. Segal, L.; Creely, J. J.; Martin-Jr, A. E.; Conrad, C. M., Textile Research Journal 1959, 29 (10), 786-794.

42. Eronen, P.; Osterberg, M.; Heikkinen, S.; Tenkanen, M.; Laine, J., Carbohydrate Polymers 2011, 86 (3), 1281-1290.

43. Asikainen, S.; Fuhrmann, A.; Robertsen, L., Nordic Pulp \& Paper Research Journal 2010, 25 (3), 269-276.

44. Yamamoto, H.; Horii, F., Macromolecules 1993, 26 (6), 1313-1317.

45. Heng, J. Y. Y.; Pearse, D. F.; Thielmann, F.; Lampke, T.; Bismarck, A., Compos. Interfaces 2007, 14 (7-9), 581-604.

46. Papirer, E.; Brendle, E.; Balard, H.; Vergelati, C., J. Adhes. Sci. Technol. 2000, 14 (3), 321-337.

47. Luner, P.; Sandell, M., Journal of Polymer Science Part C 1969, 28, 115-142.

48. Sun, C. H.; Berg, J. C., Advances in Colloid and Interface Science 2003, 105, 151-175.

49. Stana-Kleinschek, K.; Ribitsch, V., Colloids and Surfaces a-Physicochemical and Engineering Aspects 1998, 140 (1-3), 127-138.

50. Holmbom, B.; Sundberg, A.; Strand, A., Surface-active compounds as forestindustry by-products. In Surfactants from renewable resources, Kjellin, M.; Johansson, I., Eds. John WIley and Sons Ltd: Chippenham, 2010.

51. van Wazer, J., Phosphorus and its compounds vol I. Interscience Encyclopedia Inc: New York, 1958.

52. Hansen, N. M. L.; Plackett, D., Biomacromolecules 2008, 9 (6), 1493-1505.

53. Pott, G. T., Natural fibers with low moisture sensitivity. In Natural fibers, plastics and composites, Wallenberger, F. T.; Weston, N., Eds. Kluwer Academic: Norwell, 2004; pp 105-122.

54. Zhironkin, A. N.; Volkov, V. A., Colloid Journal of the Russian Academy of Sciences 1992, 54 (4), 470-475. 
55. Baltazar-Y-Jimenez, A.; Bismarck, A., Cellulose 2007, 14 (2), 115-127.

56. U.S.D.A Thermal degradation of wood componenets; U.S. Department of Agriculture, Forest Service, Forest Laboratory Madison, 1970.

57. Seifert, M.; Hesse, S.; Kabrelian, V.; Klemm, D., J. Polym. Sci. Pol. Chem. 2004, 42 (3), 463-470.

58. Cheng, K.-C.; Catchmark, J. M.; Demirci, A., J Bio Eng 2009, 3 (12).

59. Um, I. C.; Ki, C. S.; Kweon, H. Y.; Lee, K. G.; Ihm, D. W.; Park, Y. H., Int. J. Biol. Macromol. 2004, 34 (1-2), 107-119.

60. Iwamoto, S.; Abe, K.; Yano, H., Biomacromolecules 2008, 9 (3), 1022-1026.

61. Molin, U.; Teder, A., Nordic Pulp \& Paper Research Journal 2002, 17 (1), 14-19.

62. Grondahl, M.; Eriksson, L.; Gatenholm, P., Biomacromolecules 2004, 5 (4), $1528-1535$. 


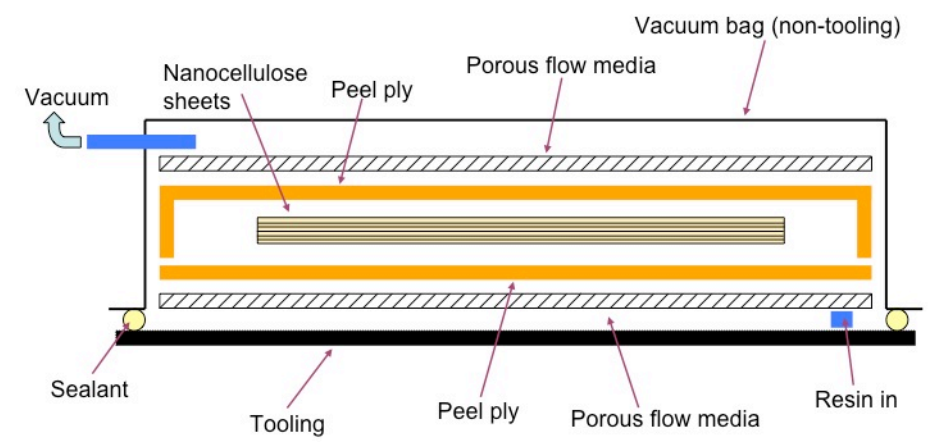

Figure 1. Schematic diagram of the VARI process.

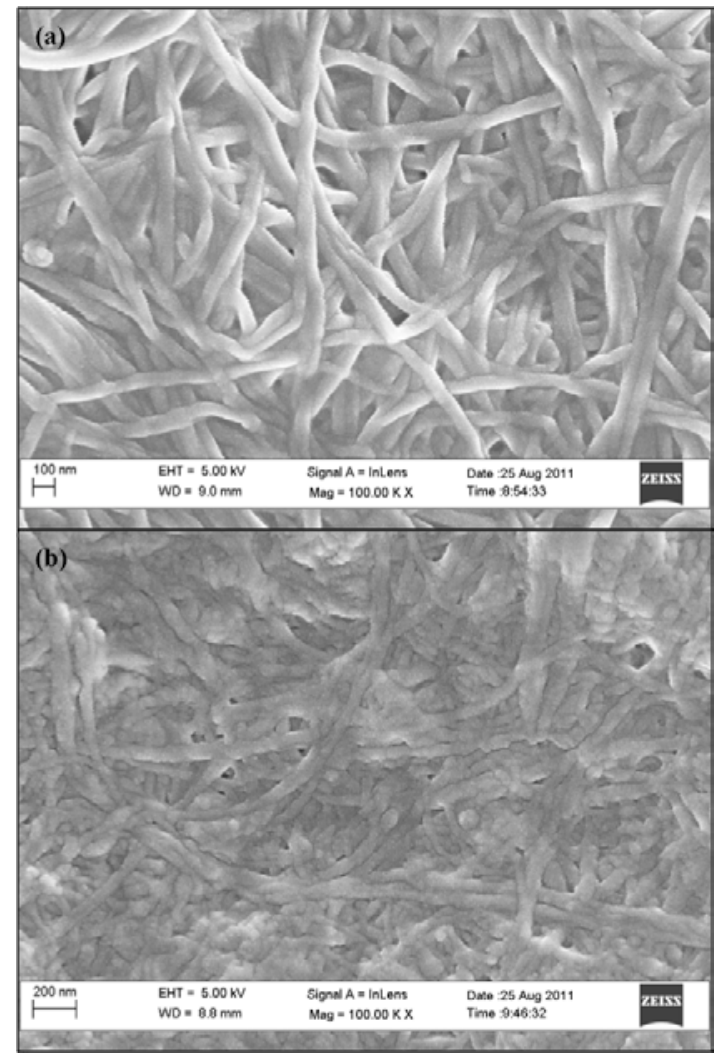

Figure 2. Scanning electron micrographs of (a) BC nanofibres and (b) NFC.

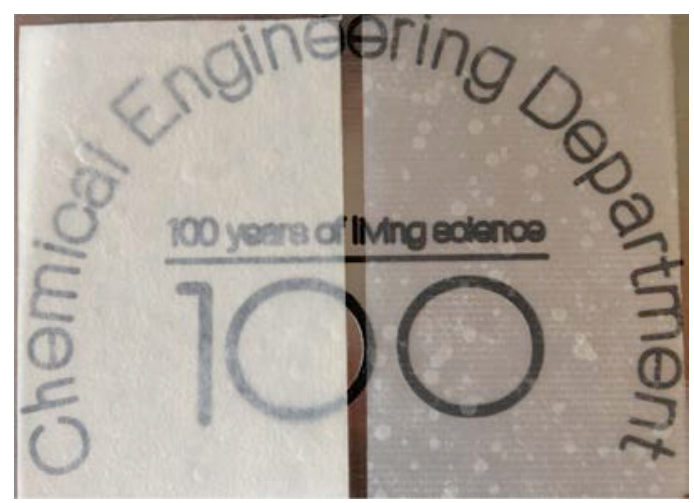

Figure 3. A comparison of the optical transparency of NFC and BC papers. Left: BC paper and right: NFC paper. 


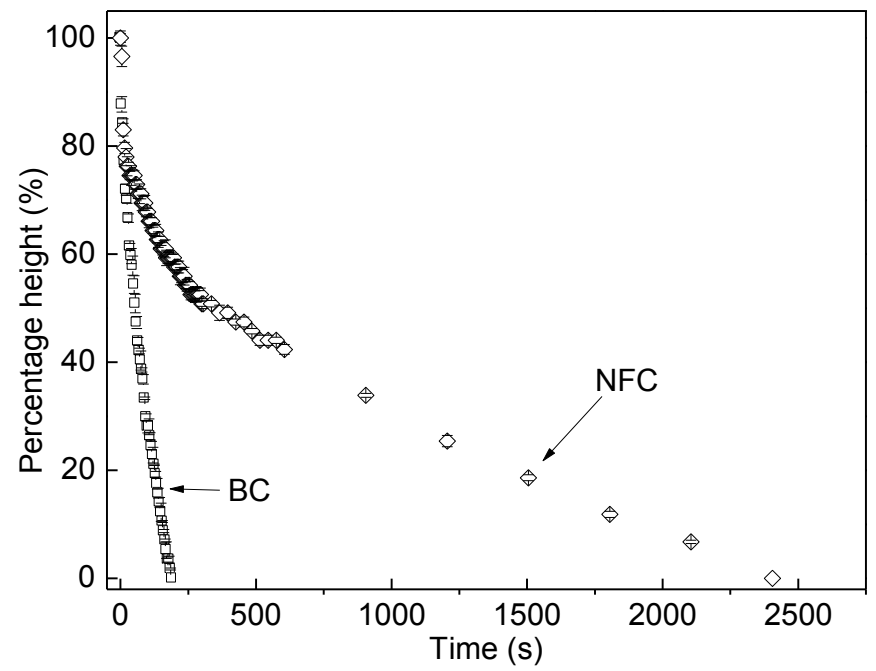

Figure 4. The height of the nanocellulose suspension as a function of time during vacuum filtration.

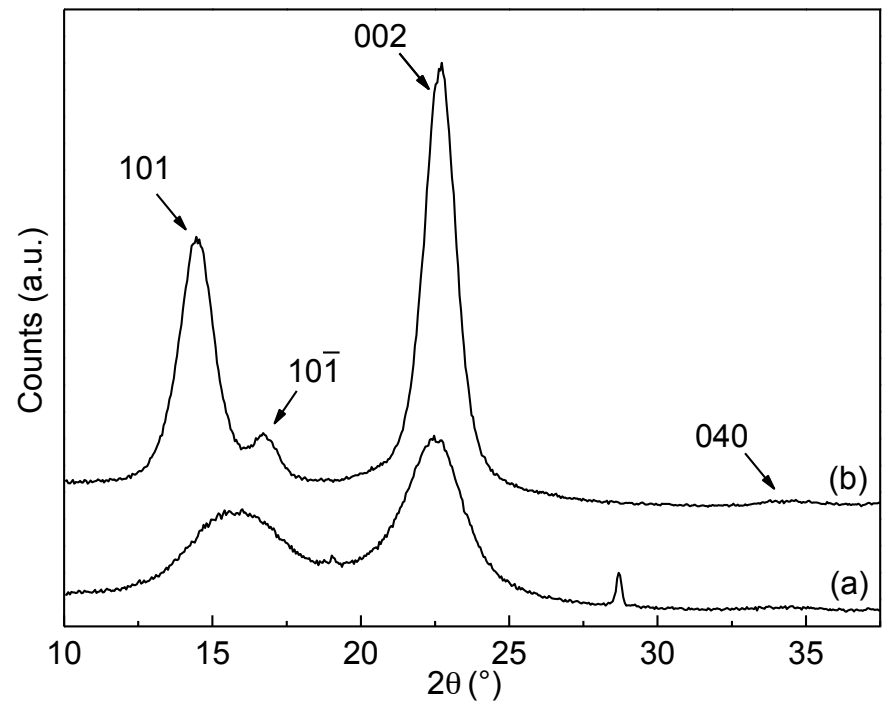

Figure 5. X-ray diffraction pattern of (a) NFC and (b) BC.

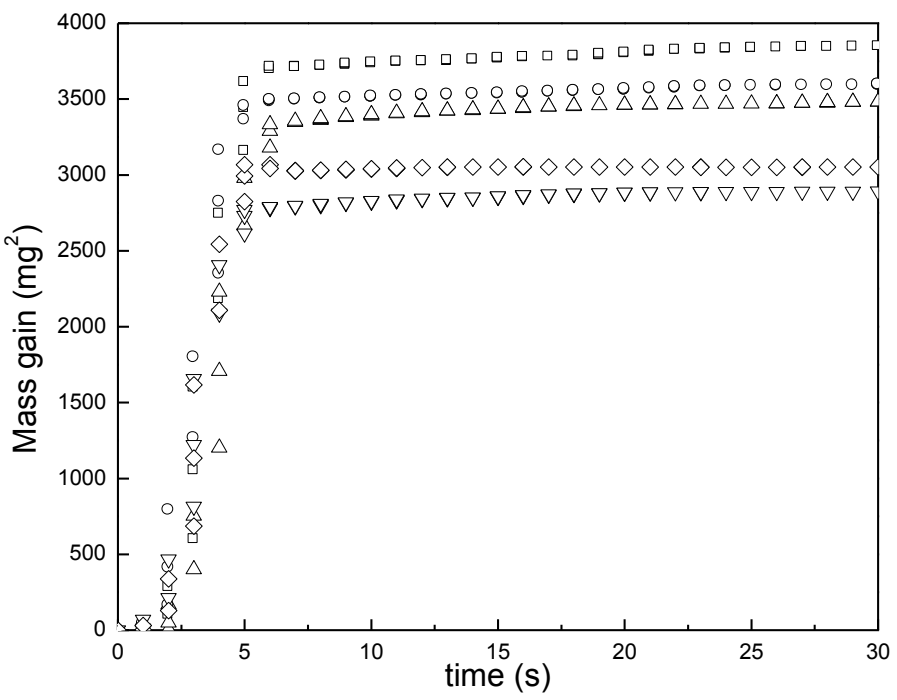

Figure 6. Typical wetting curves of $\mathrm{BC}$ by water. 


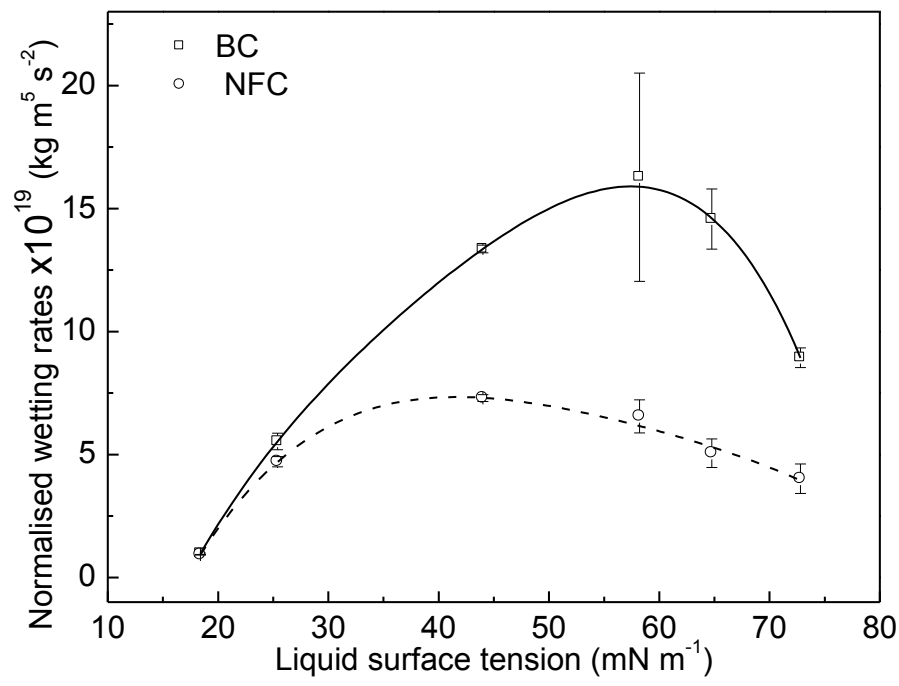

Figure 7. Normalised wetting rates as a function of the surface tension of test liquids for NFC and BC.

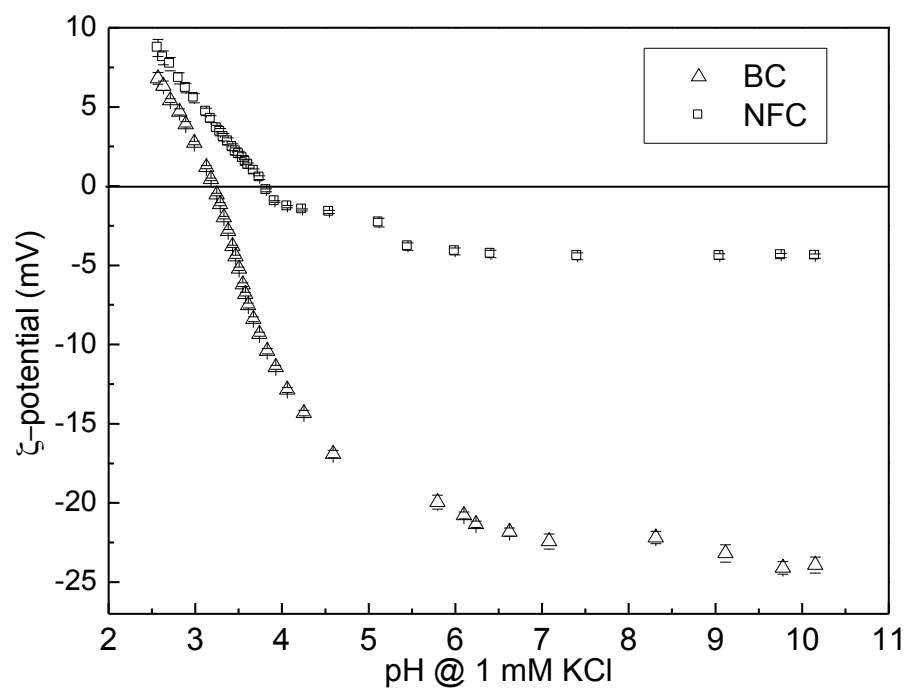

Figure 8. $\zeta=\mathbf{f}(\mathrm{pH})$ of $\mathrm{NFC}$ and $\mathrm{BC}$ papers. 

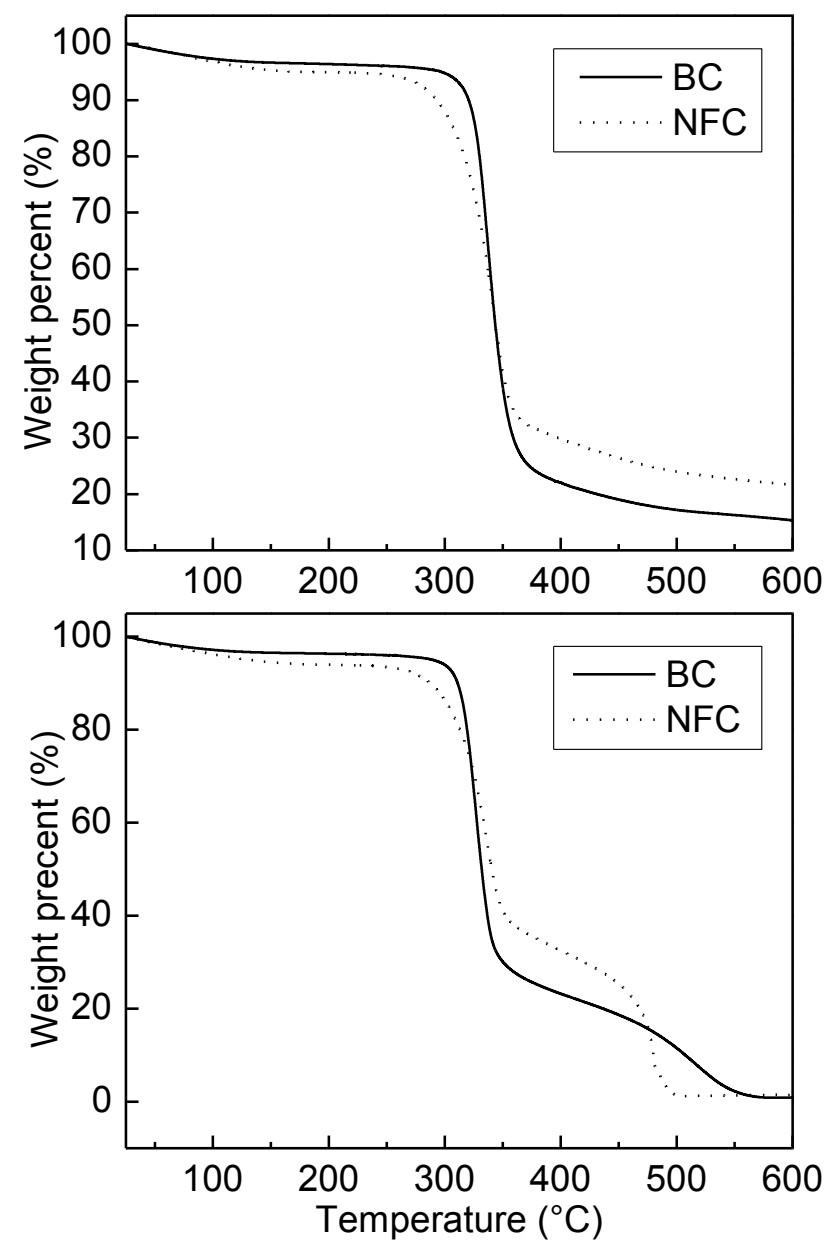

Figure 9. Thermal degradation behaviour of NFC and BC in nitrogen (top) and air (bottom), respectively. 

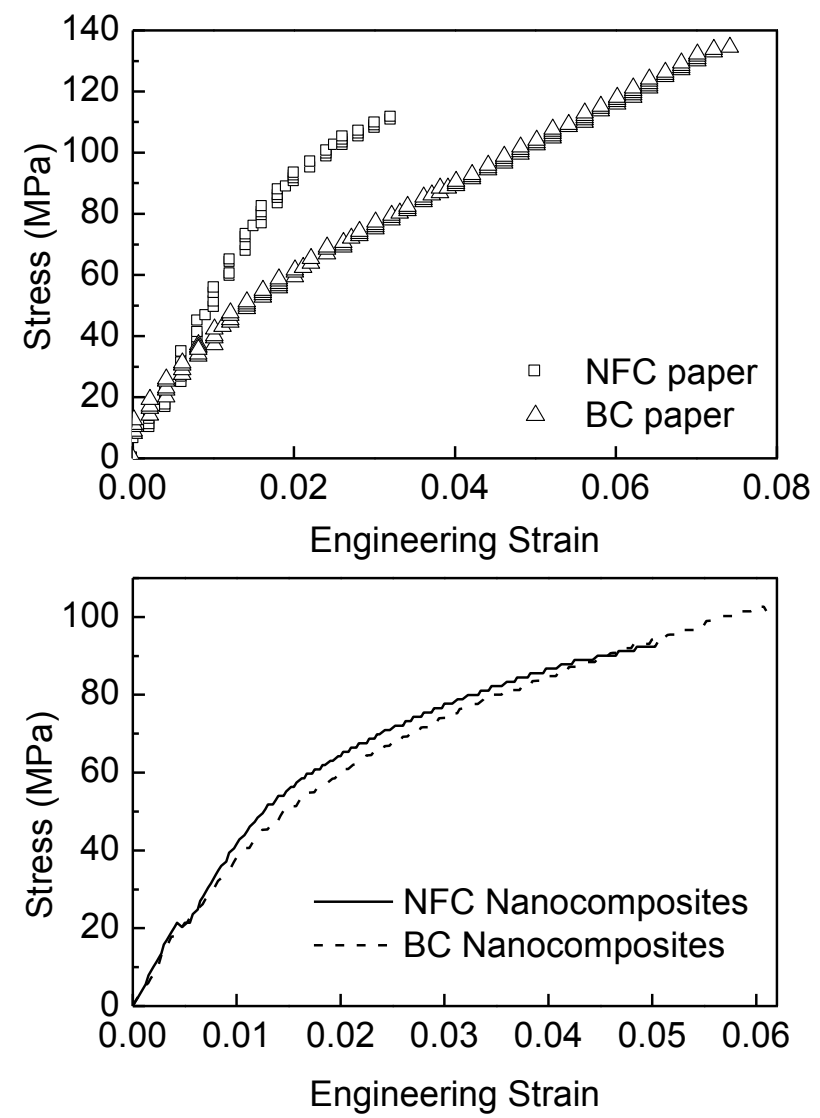

Figure 10. Characteristic stress strain curves of NFC and BC papers (top), and NFC and BC reinforced nanocomposites (bottom). 
Table 1. Properties of the test liquids used for wetting measurements. $\gamma_{\mathrm{lv}}, \eta, \rho$ are the liquid surface tension, viscosity and density, respectively.

\begin{tabular}{llll}
\hline Test liquid & $\gamma_{\mathrm{lv}}\left(\mathrm{mN} \mathrm{m}^{-1}\right)$ & $\eta(\mathrm{mPa} \mathrm{s})$ & $\rho\left(\mathrm{g} \mathrm{cm}^{-3}\right)$ \\
\hline n-Hexane & 18.4 & 0.326 & 0.664 \\
n-Dodecane & 25.4 & 1.350 & 0.749 \\
Dimethyl sulfoxide & 44.0 & 2.140 & 1.104 \\
Formamide & 58.2 & 3.812 & 1.133 \\
Ethylene glycol: water (20: 80 wt/wt) & 64.8 & 1.331 & 1.109 \\
Water & 72.8 & 1.002 & 0.998 \\
\hline
\end{tabular}

Table 2. A comparison of the crystallinity $\left(\chi_{c}\right)$, d-spacing $\left(d_{(002)}\right)$, the crystallite size of the 002 reflection $\left(\mathrm{L}_{(002)}\right)$ and the hydrodynamic diameter $\left(\mathrm{d}_{\mathrm{H}}\right)$, respectively.

\begin{tabular}{|c|c|c|c|c|}
\hline $\begin{array}{l}\text { Types of } \\
\text { nanocellulose }\end{array}$ & $\begin{array}{l}\chi_{c} \\
(\%)\end{array}$ & $\begin{array}{l}\mathrm{d}_{(002)} \\
(\AA)\end{array}$ & $\begin{array}{l}\mathrm{L}_{(002)} \\
(\AA)\end{array}$ & $\begin{array}{l}\mathrm{d}_{\mathrm{H}} \\
(\mu \mathrm{m})\end{array}$ \\
\hline $\mathrm{NFC}$ & $41 \pm 5$ & $8.07 \pm 0.01$ & $31.82 \pm 0.32$ & $16 \pm 1$ \\
\hline $\mathrm{BC}$ & $72 \pm 1$ & $7.99 \pm 0.01$ & $62.94 \pm 0.15$ & $34 \pm 3$ \\
\hline
\end{tabular}

Table 3. The critical surface energy $\left(\gamma_{c}\right)$, isoelectric point (iep), $\zeta_{\text {plateau }}, \Delta \zeta$ and the onset degradation temperature in $\mathrm{N}_{2}\left(\mathrm{~T}_{\mathrm{d}, \mathrm{N} 2}\right)$ and air $\left(\mathrm{T}_{\mathrm{d}, \text { air }}\right)$ of NFC and BC papers, respectively.

\begin{tabular}{lllllll}
\hline \multirow{2}{*}{ Nanocellulose } & $\begin{array}{l}\gamma_{\mathrm{c}} \\
\left(\mathrm{mN} \mathrm{m}^{-1}\right)\end{array}$ & $\begin{array}{l}\text { iep } \\
(\mathrm{pH})\end{array}$ & $\begin{array}{l}\zeta_{\text {plateau }} \\
(\mathrm{mV})\end{array}$ & $\Delta \zeta^{\mathrm{a}}$ & $\begin{array}{l}\mathrm{T}_{\mathrm{d}, \text { air }} \\
\left({ }^{\circ} \mathrm{C}\right)\end{array}$ & $\begin{array}{l}\mathrm{T}_{\mathrm{d}, \mathrm{N} 2} \\
\left({ }^{\circ} \mathrm{C}\right)\end{array}$ \\
\hline NFC & $41.7 \pm 0.8$ & $3.8 \pm 0.1$ & $-4.3 \pm 0.1$ & 0.125 & $244 \pm 1$ & $247 \pm 2$ \\
$\mathrm{BC}$ & $57.0 \pm 0.2$ & $3.2 \pm 0.1$ & $-22.9 \pm 0.9$ & 0.064 & $289 \pm 1$ & $294 \pm 1$ \\
\hline${ }^{\mathrm{a}} \Delta \zeta=\left(\zeta_{\infty}-\zeta_{0}\right) / \zeta_{0}$ & & & & & &
\end{tabular}

Table 4. Mechanical properties and the properties of NFC and BC papers. $E_{\text {paper }}, \sigma_{\text {paper }}, \varepsilon_{\text {paper }}$ and $W_{A}$ indicate Young's modulus, tensile strength, elongation at break and work of fracture, respectively.

\begin{tabular}{llllll}
\hline $\begin{array}{l}\text { Types of } \\
\text { nanocellulose }\end{array}$ & $\begin{array}{l}\mathrm{E}_{\text {paper }} \\
(\mathrm{GPa})\end{array}$ & $\begin{array}{l}\sigma_{\text {paper }} \\
(\mathrm{MPa})\end{array}$ & $\begin{array}{l}\varepsilon_{\text {paper }} \\
(\%)\end{array}$ & $\begin{array}{l}\text { grammage } \\
\left(\mathrm{g} \mathrm{m}^{-2}\right)\end{array}$ & $\begin{array}{l}\mathrm{W}_{\mathrm{A}} \\
\left(\mathrm{MJ} \mathrm{m}^{-3}\right)\end{array}$ \\
\hline NFC & $12.8 \pm 1.4$ & $103 \pm 13$ & $4.2 \pm 0.8$ & $59.5 \pm 0.4$ & $3.8 \pm 0.7$ \\
BC & $12.0 \pm 1.1$ & $123 \pm 7$ & $7.5 \pm 0.6$ & $57.2 \pm 3.2$ & $5.8 \pm 0.6$ \\
\hline
\end{tabular}

Table 5. The bulk density ( $\left.\rho_{\text {bulk }}\right)$, true density $\left(\rho_{\text {cell }}\right)$, porosity $(\%)$ and oxygen transmission rate $\left(\mathrm{OTR}_{\mathrm{O} 2}\right)$ of NFC and $\mathrm{BC}$, respectively.

\begin{tabular}{lllll}
\hline Nanocellulose & $\rho_{\text {bulk }}\left(\mathrm{g} \mathrm{cm}^{-3}\right)$ & $\rho_{\text {cell }}\left(\mathrm{g} \mathrm{cm}^{-3}\right)$ & $\mathrm{P}(\%)$ & $\begin{array}{l}\mathrm{OTR}_{\mathrm{O} 2} \\
\left(\mathrm{~cm}^{3} \mathrm{~mm} \mathrm{~m}^{-2} \mathrm{~d}^{-1}\right)\end{array}$ \\
& & & & \\
\hline NFC & $0.93 \pm 0.01$ & $1.51 \pm 0.02$ & $38.4 \pm 0.7$ & 4.5 \\
BC & $0.72 \pm 0.02$ & $1.54 \pm 0.05$ & $52.3 \pm 2.2$ & 5.4 \\
\hline
\end{tabular}


Table 6. Fibre volume fraction $\left(\mathrm{v}_{\mathrm{f}}\right)$ and the mechanical properties of the nanocomposites. $E$, $E_{n o r m}, \sigma$ and $\varepsilon$ indicate the Young's modulus, normalised Young's modulus to 60 vol.-\%, tensile strength and the engineering elongation at break ( $\varepsilon$ ) of the nanocomposites, respectively. The errors tabulated are standard errors.

\begin{tabular}{llllll}
\hline $\begin{array}{l}\text { Types of } \\
\text { nanocellulose }\end{array}$ & $\begin{array}{l}\mathrm{v}_{\mathrm{f}} \\
(\text { vol.-\% } \%)\end{array}$ & $\begin{array}{l}\mathrm{E} \\
(\mathrm{GPa})\end{array}$ & $\begin{array}{l}\mathrm{E}_{\text {norm }}=\left(\mathrm{E} / \mathrm{v}_{\mathrm{f}}\right) \times 0.6 \\
(\mathrm{GPa})\end{array}$ & $\begin{array}{l}\sigma \\
(\mathrm{MPa})\end{array}$ & $\begin{array}{l}\varepsilon \\
(\%)\end{array}$ \\
\hline $\begin{array}{l}\text { Neat resin } \\
\text { NFC }\end{array}$ & 0 & 3.0 & - & 71 & 6.3 \\
$\begin{array}{l}\text { nanocomposites } \\
\text { BC }\end{array}$ & $58 \pm 1$ & $8.5 \pm 0.2$ & $8.8 \pm 0.2$ & $96 \pm 1$ & $5.3 \pm 0.5$ \\
$\begin{array}{l}\text { nanocomposites } \\
\text { \& }\end{array}$ & $49 \pm 2$ & $7.1 \pm 0.1$ & $8.7 \pm 0.2$ & $102 \pm 1$ & $5.9 \pm 0.2$ \\
\hline
\end{tabular}




\section{Table of content}

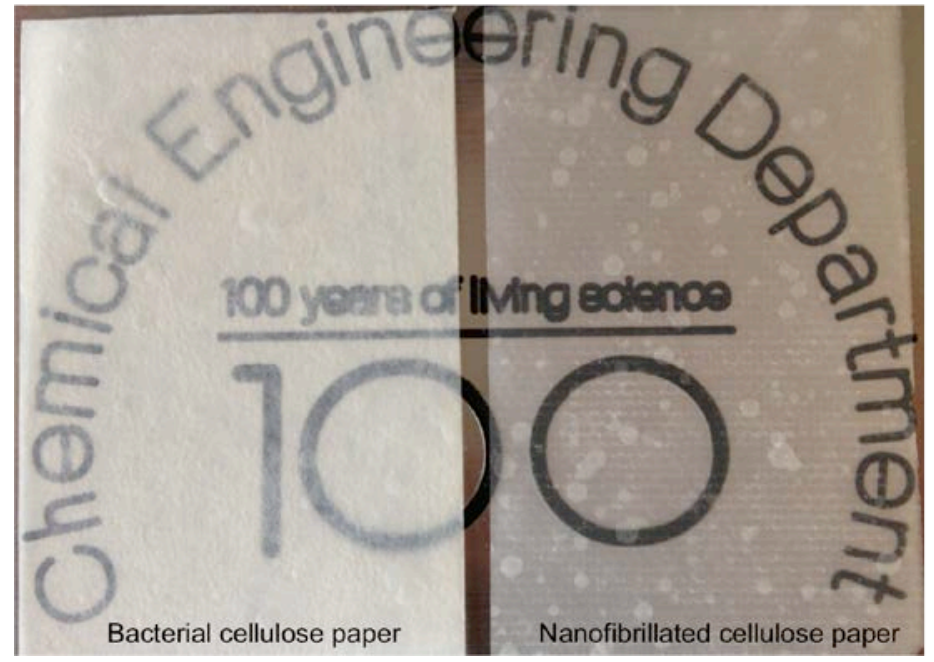

